\title{
Pengaruh Endorsement Beauty Vlogger, Country Of Origin Dan Perceived Quality Terhadap Minat Beli Produk Kosmetik Mascara Maybelline (Studi pada Mahasiswa di Beberapa Universitas di Purwokerto)
}

\author{
Anggita Widianingsih ${ }^{(1)}$ \\ Program Studi Manajemen S1 \\ Fakultas Ekonomi dan Bisnis Universitas Muhammadiyah Purwokerto ${ }^{(1)}$

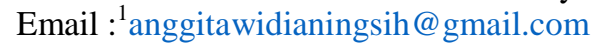 \\ Herni Justiana Astuti ${ }^{(2)}$ \\ Program Studi Manajemen S1 \\ Fakultas Ekonomi dan Bisnis Universitas Muhammadiyah Purwokerto ${ }^{(2)}$ \\ Email : ${ }^{2}$ herni99@gmail.com
}

\begin{abstract}
ABSTRAK
Tujuan dari penelitian ini adalah untuk menganalisis pengaruh endorsement beauty vlogger, country of origin, dan perceived quality terhadap minat beli produk kosmetik mascara Maybelline. Kuesioner digunakan sebagai alat pengumpulan data. Metode Purposive Sampling digunakan untuk memilih 90 sampel dengan beberapa kriteria yang telah ditentukan. Analisis data menggunakan Structural Equation Modeling pendekatan Partial Least Square. Hasil dari penelitian mengungkapkan bahwa endorsement beauty vlogger, perceived quality berpengaruh positif signifikan terhadap minat beli, country of origin berpengaruh positif signifikan terhadap perceived quality dan country of origin berpengaruh signifikan terhadap minat beli melalui perceived quality. Sedangkan country of origin tidak berpengaruh terhadap minat beli.

Kata Kunci : endorsement beauty vlogger, country of origin, perceived quality, minat beli.
\end{abstract}

\section{ABSTRACT}

The purpose of this study is to analyze the effect beauty vlogger endorsement, country of origin, and perceived quality towards purchasing intention. The questionnaire is used as a data collection tool. Purposive sampling method is used to select 90 samples with several predetermined criteria. Data analysis used was Structural Equation Modeling approach to Partial Least Square. The results of the study showed that beauty vlogger endorsement and perceived quality had a positive significant effect on purchasing intention, country of origin had a positive significant effect on perceived quality and country of origin had a significant effect on purchase intention with through of perceived quality. While country of origin has no effect on purchasing intention.

Keywords : beauty vlogger endorsement, country of origin, perceived quality, purchase intention

\section{PENDAHULUAN}

Dewasa ini pembelian suatu produk kosmetik bukan lagi untuk memenuhi keinginan saja, melainkan karena kosmetik adalah sebuah kebutuhan yang penting bahkan tidak terpisah oleh kaum wanita dalam menjalani aktivitas sehari-hari. Di Indonesia jenis kosmetik ada dua yaitu produksi dalam negeri dan produksi luar negeri. Hal tersebut menyebabkan timbulnya persaingan yang tinggi antara industri kosmetik dalam negeri dan luar negeri. Persaingan yang tinggi antar industri kosmetik mendorong para produsen kosmetik lokal maupun internasional berlomba-lomba menciptakan produk yang menjanjikan tampilan memukau (www.cnbcindonesia.com). 
Di Indonesia kosmetik memiliki peminatnya masing-masing. Ada yang lebih menyukai produk kosmetik buatan luar negeri dan ada yang menyukai produk kosmetik buatan dalam negeri. Salah satu produk kosmetik luar negeri yang diminati oleh masyarakat Indonesia adalah produk kosmetik Maybelline. Produk kosmetik Maybelline berasal dari negara Amerika Serikat tepatnya di New York. Produk kosmetik Maybelline adalah produk kosmetik yang terdiri dari brow, eyeliner, eyeshadow, mascara, bb cream, bb cushion, blush, concealer, contour, highlight, primer, fondation, powder, remover, lipbalm, lipstick, dan lip-tint (www.maybelline.co.id).

Salah satu produk merek kosmetik Maybelline yang menjadi pilihan konsumen yaitu Mascara. Mascara Maybelline selalu menjadi Top Brand dari tahun 2014 sampai tahun 2019. Top Brand adalah penghargaan yang diberikan kepada merek-merek terbaik pilihan konsumen. Dengan mendapatkan Top Brand artinya produk Mascara Maybelline menjadi merek terbaik pilihan konsumen. Tabel 1.1 terlihat bahwa Mascara Maybelline selalu menjadi Top Brand nomor satu dari tahun 2014 sampai dengan 2019, walaupun nilai Top Brand Indexnya naik turun tetapi Mascara Maybelline tetap menjadi nomor satu. Adanya Top Brand pada Mascara Maybelline bisa saja menimbulkan rasa minat bagi konsumen yang memang belum pernah memakai Mascara Maybelline untuk membeli produk tersebut. Berikut adalah tabel yang menggambarkan Top Brand Index Kategori Produk kecantikan Mascara tahun 2014-2019.

Tabel 1. Top Brand Index Kategori Kosmetik Mascara Tahun 2014-2019

\begin{tabular}{|l|c|c|c|c|c|c|}
\hline \multicolumn{1}{|c|}{ Merek } & $\begin{array}{c}\text { Tahun } \\
2014\end{array}$ & $\begin{array}{c}\text { Tahun } \\
2015\end{array}$ & $\begin{array}{c}\text { Tahun } \\
2016\end{array}$ & $\begin{array}{c}\text { Tahun } \\
2017\end{array}$ & $\begin{array}{c}\text { Tahun } \\
2018\end{array}$ & $\begin{array}{c}\text { Tahun } \\
2019\end{array}$ \\
\hline Maybelline & $24,5 \%$ & $28,7 \%$ & $25,3 \%$ & $26,8 \%$ & $22,0 \%$ & $26,2 \%$ \\
\hline Oriflame & $15,9 \%$ & $16,9 \%$ & $13,6 \%$ & $9,9 \%$ & $11,5 \%$ & $10,8 \%$ \\
\hline Revlon & $10,8 \%$ & $7,2 \%$ & $9,3 \%$ & $9,0 \%$ & $11,4 \%$ & - \\
\hline QL & - & - & $10,0 \%$ & $4,3 \%$ & $9,5 \%$ & - \\
\hline Wardah & - & - & - & $12,2 \%$ & $19,0 \%$ & $15,5 \%$ \\
\hline La Tulipe & $4,2 \%$ & - & - & - & - & $10,9 \%$ \\
\hline
\end{tabular}

Sumber : www.topbrand-award.com

Ada beberapa faktor yang mempengaruhi minat beli, seperti endorsement beauty vlogger, country of origin, dan perceived quality. Faktor pertama adalah endorsement beauty vlogger. Endorsement adalah segala bentuk pesan yang diberikan dalam kegiatan pemasaran, dimana konsumen cenderung mempercayai opini, keyakinan, pendapat, atau pengalaman dari pihak lain selain perusahaan tersebut sebagai sponsor (Tobin, 1975 dalam Hutapea, 2016). Menurut Widodo dan Mawardi (2017:64) beauty vlogger adalah seseorang yang membuat serta mengunggah video tentang kecantikan. Kecantikan di sini diartikan sebagai apa yang digunakan berkaitan dengan skincare, makeup, atau alat kecantikan lainnya oleh vlogger. Sehingga dapat disimpulkan bahwa endorsement beauty vlogger merupakan seseorang atau kelompok yang membuat vlog bertujuan untuk merekomedasikan dan mengulas tentang kecantikan serta produk yang digunakan. Hasil penelitian Anggraeni dkk (2018), Sinaga dan Kusumawati (2018), Widodo dan Mawardi (2017), Sunarti dkk (2019) dan hasil penelitian Andjarwati dan Dewi (2019) yang menyatakan bahwa endorsement beauty vlogger berpengaruh positif signifikan terhadap minat beli.

Adapaun faktor kedua yang berpengaruh terhadap minat beli adalah country of origin. Menurut Kotler dan Keller (2009:338) country of origin adalah asosiasi dan kepercayaan mental seseorang akan suatu produk yang dipicu oleh negara asal suatu 
produk. Hasil penelitian Susmikawati dan Sunarti (2017), Dinata dkk (2015), Izzuddien dkk (2018), dan Adenan dkk (2018) yang menyatakan bahwa country of origin berpengaruh positif signifikan terhadap minat beli. Namun hasil penelitian dari Rafida (2015), Berlianto (2019) dan Le dkk (2017) menyatakan bahwa country of origin tidak berpengaruh terhadap minat beli. Selain country of origin berpengaruh terhadap minat beli, country of origin juga berpengaruh terhadap perceived quality. Hasil penelitian Susmikawati dan Sunarti (2017), Dinata dkk (2015), Izzuddien dkk (2018) dan Le dkk (2017) yang menyatakan bahwa country of origin berpengaruh positif signifikan terhadap perceived quality.

Faktor ketiga yang berpengaruh terhadap minat beli adalah perceived quality. Menurut Menurut Schiffman dan Kanuk (2018:163) persepsi kualitas merupakan penilaian kualitas produk atau jasa tertentu atas dasar berbagai macam isyarat informasi baik yang bersifat intrinsik maupun ekstrinsik. Hasil penelitian Susmikawati dan Sunarti (2017), Dinata dkk (2015), Izzuddien dkk (2018), Ardelia dan Supriono (2017), Le dkk (2017), Tansil dan Tielung (2014), dan Li (2017) yang menyatakan bahwa perceived quality berpengaruh positif signifikan terhadap minat beli. Namun hasil penelitian dari Asdiansyuri dan Octavia (2018) menyatakan bahwa perceived quality tidak berpengaruh terhadap minat beli.

Penelitian yang akan dilakukan ini merupakan penelitian pengembangan dari penelitian terdahulu yang dilakukan oleh Susmikawati dan Sunarti (2017) dengan mengambil variabel yaitu country of origin dan perceived quality karena variabel tersebut berpengaruh secara positif signifikan terhadap minat beli. Adapun perbedaan penelitian ini dengan penelitian sebelumnya terletak pada variabel independennya. Dalam penelitian ini peneliti menambahkan variabel endorsement beauty vlogger dari penelitian terdahulu yang dilakukan oleh Anggraeni dkk (2018) karena variabel tersebut berpengaruh secara positif signifikan terhadap minat beli. Alasan peneliti menambahkan variabel endorsement beauty vlogger karena ingin mencari faktor lain yang dapat mempengaruhi minat beli. Berdasarkan dari ulasan latar belakang masalah dan adanya perbedaan hasil penelitian terdahulu, maka peneliti tertarik untuk melakukan penelitian dengan judul "Pengaruh Endorsement Beauty Vlogger, Country of Origin dan Perceived Quality Terhadap Minat Beli Produk Kosmetik Mascara Maybelline".

\section{Rumusan Masalah}

Berdasarkan uraian dari latar belakang di atas, maka rumusan masalah dalam penelitian ini adalah : (1) apakah endorsement beauty vlogger berpengaruh positif signifikan terhadap minat beli produk Mascara Maybelline di Purwokerto? (2) apakah country of origin berpengaruh positif signifikan terhadap minat beli produk Mascara Maybelline di Purwokerto? (3) apakah country of origin berpengaruh positif signifikan terhadap perceived quality produk Mascara Maybelline di Purwokerto? (4) apakah perceived quality berpengaruh positif signifikan terhadap minat beli produk Mascara Maybelline di Purwokerto? (5) apakah country of origin berpengaruh signifikan terhadap minat beli melalui perceived quality pada produk Mascara Maybelline di Purwokerto?

\section{TINJAUAN PUSTAKA \\ Endorsement Beauty Vlogger}

Endorsement merupakan salah satu bentuk komunikasi pemasaran. Endorsement adalah segala bentuk pesan yang diberikan dalam kegiatan pemasaran, dimana konsumen cenderung mempercayai opini, keyakinan, pendapat, atau pengalaman dari pihak lain selain perusahaan tersebut sebagai sponsor (Tobin, 1975 dalam Hutapea, 2016). Vlogger adalah orang yang membuat Vlog (Video blog) yang berisikan materi post berupa video. 
Jenis video ini biasanya menampilkan rekaman profil seseorang, aktivitas sehari-hari yang dilakukan oleh orang tersebut, serta pengalaman-pengalaman yang dirasakan dan sebagainya (Media, 2009) dalam Sinaga dan Kusumawati (2018).

Terdapat beberapa macam jenis vlogger yang saat ini berkembang, salah satunya adalah beauty vlogger. Menurut Widodo dan Mawardi (2017:64) beauty vlogger adalah seseorang yang membuat serta mengunggah video tentang kecantikan. Kecantikan di sini dapat diartikan sebagai sesuatu yang berkaitan dengan skincare, makeup, atau alat kecantikan lainnya oleh vlogger. Endorsement beauty vlogger memberikan penampilan yang baik akan menarik dan menimbulkan minat terhadap produk tersebut. Produk juga akan cepat dikenal oleh konsumen karena informasi yang diberikan oleh endorsement beuty vlogger yang detail (Anggraeni dkk (2018).

\section{Country of Origin}

Menurut Kotler dan Keller (2009:338) country of origin adalah asosiasi dan kepercayaan mental seseorang akan suatu produk yang dipicu oleh negara asal suatu produk. Pembeli mempunyai sikap dan kepercayaan berbeda tentang merek atau produk dari berbagai negara. Menurut Schiffman dan Kanuk (2018:412) country of origin adalah sikap seseorang mengenai suatu produk tertentu yang dibuat oleh suatu negara yang akhirnya mempengaruhi bagaimana para konsumen menilai kualitas dan merk-merk yang akan dipilih.

Menurut Schiffman dan Kanuk (2018:162) persepsi kualitas merupakan penilaian kualitas produk atau jasa tertentu atas dasar berbagai macam isyarat informasi baik yang bersifat intrinsik maupun ekstrinsik. Menurut Aaker (1997) dalam Dinata dkk (2015) persepsi kualitas merupakan persepsi konsumen terhadap keseluruhan kualitas atau keunggulan suatu produk, atau jasa layanan berkaitan dengan maksud yang diharapkan.Sedangkan menurut Sinamora (2003:78) dalam Dinata dkk (2015) persepsi kualitas merupakan perasaan konsumen pada sebuah merek atau produk dan tidak dapat ditetapkan secara objektif.

\section{Minat Beli}

Menurut Kotler dan Keller (2012) dalam Priansa (2017:164) menyatakan bahwa minat pembelian adalah perilaku konsumen yang mucul sebagai respon terhadap objek yang menunjukkan keinginan seseorang untuk melakukan pembelian. Menurut Priansa (2017:164) minat pembelian merupakan pemusatan perhatian suatu yang disertai dengan perasaan senang terhadap barang tersebut, kemudian minat individu tersebut menimbulkan keinginan sehingga timbul perasaan yang menyakinkan barang tersebut mempunyai manfaat sehingga individu ingin memiliki barang tersebut dengan cara membayar atau menukar dengan uang.

Menurut Howard dan Sheth (1969) dalam Priansa (2017:164) minat pembelian adalah sesuatu yang berhubungan dengan rencana konsumen untuk membeli produk tertentu serta berapa banyak unit produk yang dibutuhkan pada periode tertentu. Dapat dikatakan bahwa minat pembelian merupakan pernyataan mental dari konsumen yang merefleksikan rencana pembelian sejumlah produk dengan merek tertentu. Hal ini sangat diperlukan oleh para pemesan untuk mengetahui minat pembelian konsumen terhadap suatu produk, baik para pemasar maupun ahli ekonomi menggunakan variabel minat untuk memprediksi perilaku konsumen di masa yang akan datang.

\section{Hipotesis}

H1 : Endorsement beauty vlogger berpengaruh positif signifikan terhadap minat beli

$\mathrm{H} 2$ : Country of origin berpengaruh positif signifikan terhadap minat beli 
H3 : Country of origin berpengaruh positif signifikan terhadap peceived quality

H4 : Perceived quality berpengaruh positif signifikan terhadap minat beli

H5 : Country of origin berpengaruh signifikan terhadap minat beli melalui perceived quality

\section{METODE ANALISIS DATA}

Responden dalam penelitian ini adalah mahasiswa yang berminat membeli produk Mascara Maybelline yaitu mahasiwa Universitas Muhammadiyah Purwokerto, Intitut Agama Islam Negeri Purwokerto, dan Universitas Jenderal Soedirman. Analisis data menggunakan PLS-SEM 3.0. Analisis PLS-SEM biasanya terdiri dari dua sub model yaitu model pengukuran (measurement model) atau sering disebut outer model dan model struktural (structural model) atau sering disebut inner model.

\section{HASIL DAN PEMBAHASAN}

\section{Uji Model Pengukuran (Outer Model)}

Evaluasi model pengukuran atau outer model dilakukan untuk menilai validitas dan reliabilitas model. Outer model dengan indikator refleksif dievaluasi melalui validitas convergent dan discriminant dari indikator pembentuk konstruk laten dan composite reliability untuk blok indikatornya. Dalam outer model mengukur nilai outer loading > 0,5-0,6, nilai AVE > 0,5, dan nilai composite reliability 0,7.

Tabel 2. Variabel, Indikator, Loading Factor Putaran 1, Loading Factor Putaran 2,

Loading Factor Putaran 3, AVE and Composite Reliability

\begin{tabular}{|c|c|c|c|c|c|c|}
\hline Variabel & Indikator & $\begin{array}{l}\text { Loading } \\
\text { Factor } \\
\text { Putaran } 1\end{array}$ & $\begin{array}{l}\text { Loading } \\
\text { Factor } \\
\text { Putaran } \\
2\end{array}$ & $\begin{array}{l}\text { Loading } \\
\text { Factor } \\
\text { Putaran } \\
3\end{array}$ & AVE & $\begin{array}{l}\text { Composite } \\
\text { Reliability }\end{array}$ \\
\hline \multirow{5}{*}{$\begin{array}{l}\text { Endorsement } \\
\text { Beauty } \\
\text { Vlogger } \\
(\text { Shimp } \\
(2014: 260)\end{array}$} & $\begin{array}{l}\text { Trustworthy/Kepercayaan } \\
\text { (EBV1) }\end{array}$ & 0,825 & 0,818 & 0,822 & \multirow[t]{5}{*}{0,676} & \multirow[t]{5}{*}{$\mathbf{0 , 8 9 2}$} \\
\hline & Expertise/ Keahlian (EBV2) & 0,359 & Ditolak & Ditolak & & \\
\hline & $\begin{array}{l}\text { Physical Attractivesness/ } \\
\text { Daya tarik fisik (EBV3) }\end{array}$ & 0,852 & 0,858 & 0,858 & & \\
\hline & $\begin{array}{l}\text { Respectl Rasa hormat } \\
\text { (EBV4) }\end{array}$ & 0,912 & 0,921 & 0,921 & & \\
\hline & $\begin{array}{l}\text { Similiary/ } \\
\text { (EBV5) }\end{array}$ & 0,668 & 0,670 & 0,667 & & \\
\hline $\begin{array}{l}\text { Country of } \\
\text { Origin }\end{array}$ & Country Beliefs (COO1) & 0,376 & Ditolak & Ditolak & \multirow[t]{3}{*}{$\mathbf{0 , 8 0 3}$} & \multirow[t]{3}{*}{0,891} \\
\hline (Laroche $\mathrm{dkk}$ & People Affect (COO2) & 0,873 & 0,889 & 0,887 & & \\
\hline (2005) dalam & Desire Interaction (COO3) & 0,910 & 0,903 & 0,905 & & \\
\hline Perceived & (performance) & 0,490 & Ditolak & Ditolak & $\mathbf{0 , 5 7 1}$ & $\mathbf{0 , 7 2 6}$ \\
\hline
\end{tabular}




\begin{tabular}{|c|c|c|c|c|c|c|}
\hline Quality & (PQ1) & & & & & \\
\hline (Tjiptono dan & Fitur (features) (PQ2) & $-0,312$ & Ditolak & Ditolak & & \\
\hline Chandra & Reliabilitas (PQ3) & 0,509 & 0,601 & Ditolak & & \\
\hline 2017) & $\begin{array}{l}\text { Konformasi (comformance) } \\
\text { (PQ4) }\end{array}$ & 0,659 & 0,666 & 0,804 & & \\
\hline & $\begin{array}{l}\text { Daya tahan (durability) } \\
\text { (PQ5) }\end{array}$ & 0,412 & Ditolak & Ditolak & & \\
\hline & Serviceability (PQ6) & 0,507 & 0,644 & 0,704 & & \\
\hline & Estetika (aesthetics) (PQ7) & 0,219 & Ditolak & Ditolak & & \\
\hline Minat Beli & Minat Transaksional (MB1) & 0,765 & 0,727 & 0,778 & $\mathbf{0 , 5 5 2}$ & $\mathbf{0 , 7 8 7}$ \\
\hline (Prinsa & Minat Referensial (MB2) & 0,765 & 0,764 & 0,750 & & \\
\hline 2017:168-169) & Minat Preferensial (MB3) & 0,249 & Ditolak & Ditolak & & \\
\hline & Minat Eksploratif (MB4) & 0,670 & 0,737 & 0,699 & & \\
\hline
\end{tabular}

\section{Uji Model Struktural (Inner model)}

Evaluasi model struktural atau inner model bertujuan untuk memprediksi hubungan antar variabel.

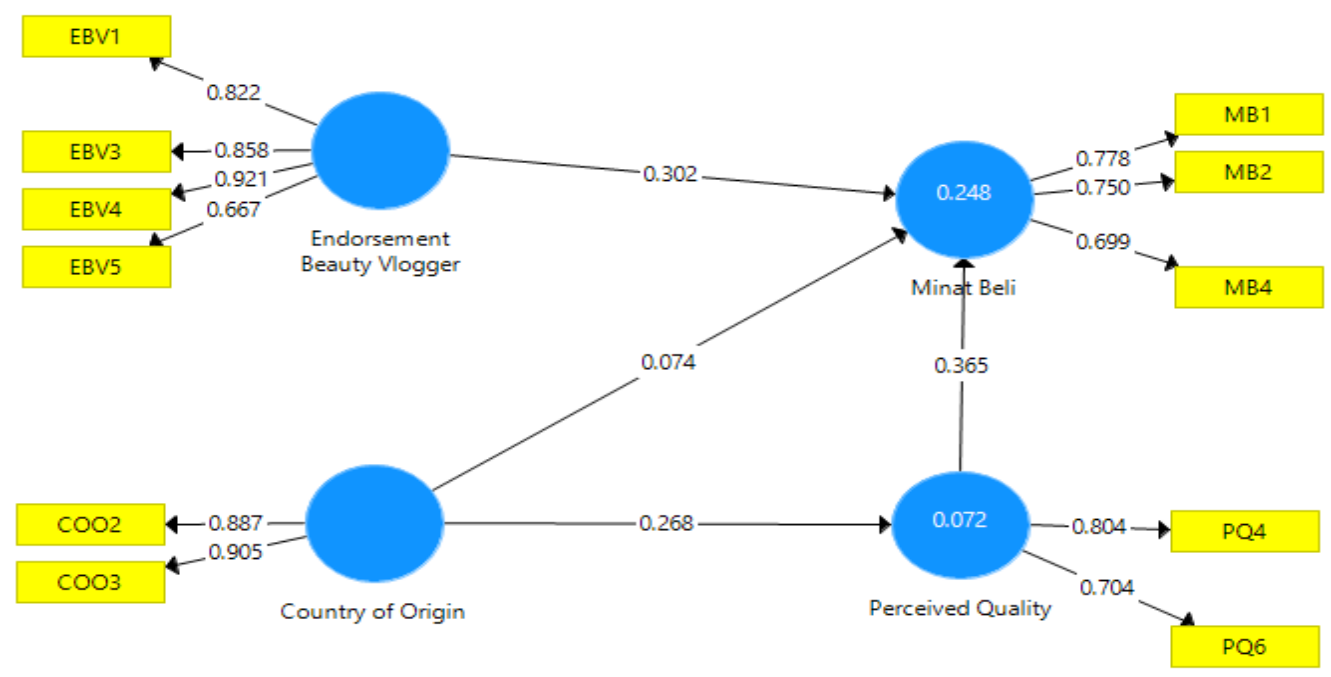

Gambar 1. Uji Model Minat Beli Putaran 3

Gambar 4.3 hasil dari PLS versi 3.0 mengenai pengaruh endorsement beauty vlogger, country of origin, dan perceived quality terhadap minat beli. Berdasarkan gambar 4.3 dapat dilihat bahwa nilai $\mathrm{R}^{2}$ 0,248 menunjukkan bahwa $24,8 \%$ variabilitas dalam konstruksi minat beli dipengaruhi oleh faktor endorsement beauty vlogger, country of origin, dan perceived quality. Sementara nilai $\mathrm{R}^{2} 0,072$ manunjukkan bahwa $7,2 \%$ variabilititas dalam konstruksi perceived quality di pengaruhi oleh faktor country of origin. 
Tabel 4.12. Hasil Penerimaan/ Penolakan Hipotesis Pengaruh Langsung

\begin{tabular}{|l|l|l|l|l|l|l|}
\hline & $\begin{array}{l}\text { Original } \\
\text { Sample } \\
(\mathrm{O})\end{array}$ & $\begin{array}{l}\text { Sample } \\
\text { Mean } \\
(\mathrm{M})\end{array}$ & $\begin{array}{l}\text { Standard } \\
\text { Deviation } \\
(\mathrm{STDEV})\end{array}$ & $\begin{array}{l}\text { Tratistics } \\
(\mid \mathrm{O} / \mathrm{STDEV})\end{array}$ & $\begin{array}{l}P \\
\text { Value }\end{array}$ & Keterangan \\
\hline $\begin{array}{l}\text { Endorsement } \\
\text { Beauty } \\
\text { Vlogger } \\
\text { Minat Beli }\end{array}$ & 0,302 & 0,314 & 0,090 & 3,367 & 0,001 & H1 Diterima \\
\hline $\begin{array}{l}\text { Country of } \\
\text { Origin } \\
\text { Minat Beli }\end{array}$ & 0,074 & 0,079 & 0,098 & 0,754 & $\mathbf{0 , 4 5 1}$ & H2 Ditolak \\
\hline $\begin{array}{l}\text { Country of } \\
\text { Origin } \\
\text { Perceived } \\
\text { Quality }\end{array}$ & 0,268 & 0,274 & 0,093 & 2,888 & 0,004 & H3 Diterima \\
\hline $\begin{array}{l}\text { Perceived } \\
\text { Quality } \\
\text { Minat Beli }\end{array}$ & 0,365 & 0,380 & 0,085 & 4,302 & 0,000 & H4 Diterima \\
\hline
\end{tabular}

Berdasarkan Tabel 4.12 semua hubungan memiliki arah positif dilihat dari nilai original sample yang menunjukkan nilai yang positif. Nilai original sample menunjukkan bahwa hubungan dapat mengarahkan pada efek positif atau negatif. Jadi faktor endorsement beauty vlogger, country of origin dan perceived quality memiliki pengaruh positif terhadap minat beli. Selain itu faktor country of origin juga memiliki pengaruh positif terhadap perceived quality.

Tabel 4.12 juga menunjukkan bahwa endorsement beauty vlogger dan perceived quality memiliki pengaruh yang signifikan terhadap minat beli dan country of origin juga memiliki pengaruh yang signifikan terhadap perceived quality dilihat dari nilai t statistic $>\mathrm{t}$ tabel $(1,66277)$ dari hasil tersebut dapat disimpulkan bahwa $\mathrm{H}_{1}, \mathrm{H}_{3}$ dan $\mathrm{H}_{4}$ diterima. Hipotesis diterima karena nilai $P$ Values $<0,05$. Namun country of origin tidak berpengaruh signifikan terhadap minat beli dilihat dari nilai $\mathrm{t}$ statistic $<\mathrm{t}$ tabel $(1,66277)$ dari hasil tersebut dapat disimpulkan bahwa $\mathrm{H}_{2}$ ditolak. Hipotesis ditolak karena nilai $\mathrm{P}$ Value $>0,05$.

Tabel 4.13. Hasil Penerimaan/ Penolakan Hipotesis Pengaruh Tidak Langsung

\begin{tabular}{|l|l|l|l|l|l|l|}
\hline & $\begin{array}{l}\text { Original } \\
\text { Sample } \\
(\mathrm{O})\end{array}$ & $\begin{array}{l}\text { Sample } \\
\text { Mean } \\
(\mathrm{M})\end{array}$ & $\begin{array}{l}\text { Standard } \\
\text { Deviation } \\
(\text { STDEV })\end{array}$ & $\begin{array}{l}T \text { Statistics } \\
(\mid \mathrm{O} / \text { STDEV|) }\end{array}$ & $\begin{array}{l}P \\
\text { Value }\end{array}$ & Keterangan \\
\hline $\begin{array}{l}\text { Country of } \\
\text { Origin } \\
\text { Perceived }\end{array}$ & 0,098 & 0,105 & 0,045 & 2,151 & 0,032 & H5 Diterima \\
$\begin{array}{l}\text { Quality } \\
\text { Minat Beli }\end{array}$ & & & & & & \\
\hline
\end{tabular}

Sumber : Lampiran 15

Berdasarkan Tabel 4.13 hubungan pengaruh country of origin terhadap minat beli melalui perceived quality memiliki arah positif dilihat dari nilai original sample yang menunjukkan nilai yang positif. Nilai original sample menunjukkan bahwa hubungan 
dapat mengarahkan pada efek positif atau negatif. Jadi faktor country of origin terhadap minat beli melalui perceived quality memiliki pengaruh positif.

Tabel 4.13 juga menunjukkan bahwa country of origin berpengaruh signifikan terhadap minat beli melalui perceived quality dilihat dari nilai $\mathrm{t}$ statistic $>\mathrm{t}$ tabel $(1,66277)$ dari hasil tersebut dapat disimpulkan bahwa $\mathrm{H}_{5}$ diterima. Hipotesis diterima karena nilai $P$ Values $<0.05$.

\section{PEMBAHASAN}

\section{Faktor Endorsement Beauty Vlogger terhadap Minat Beli}

Faktor endorsement beauty vlogger memiliki pengaruh positif dan signifikan terhadap minat beli. Dengan melihat YouTube, seseorang konsumen bisa dengan jelas melihat ulasan produk dari seorang endorsement beauty vlogger, konsumen yang mungkin tadinya tidak berminat untuk membeli setelah melihat produk yang diulas oleh seorang endorsement beauty vlogger menjadi berminat untuk membeli. Hal ini sejalan dengan hasil penelitian Anggraeni dkk (2018), Sinaga dan Kusumawati (2018), Widodo dan Mawardi (2017), Sunarti dkk (2019) dan hasil penelitian Andjarwati dan Dewi (2019) yang menyatakan bahwa endorsement beauty vlogger berpengaruh positif signifikan terhadap minat beli.

\section{Faktor Country of Origin terhadap Minat Beli}

Faktor country of origin memiliki pengaruh positif namun tidak signifikan terhadap minat beli. Dari karakteristrik responden menunjukkan bahwa responden dalam penelitian ini adalah wanita berusia muda, dimana mereka tidak terlalu memperhatikan asal negara suatu produk dalam membeli kosmetik. Bagi mereka yang penting mereka cocok dengan produk tersebut. Pernyataan ini didukung oleh hasil penelitian Sigma Research (2017) yang menyatakan bahwa 79,4\% responden mengatakan bahwa faktor kecocokan kosmetik menjadi alasan mereka membeli produk kosmetik. Hal ini sejalan dengan hasil penelitian Berlianto (2019), Rafida (2015) dan Le dkk (2017) menyatakan bahwa country of origin tidak berpengaruh terhadap minat beli. Namun hasil penelitian ini tidak sejalan dengan hasil penelitian Susmikawati dan Sunarti (2017), Dinata dkk (2015), Izzuddien dkk (2018), dan Adenan dkk (2018) yang menyatakan bahwa country of origin berpengaruh positif signifikan terhadap minat beli.

\section{Faktor Country of Origin terhadap Perceived Quality}

Faktor country of origin memiliki pengaruh positif dan signifikan terhadap perceived quality. Konsumen menganggap bahwa produk yang berasal dari luar negeri memiliki kualitas yang berbeda menurut persepsi masing-masing konsumen. Sebagai contoh produk fashion dari Paris dianggap memiliki kualitas yang tinggi dan memiliki harga jual yang tinggi. Sebaliknya konsumen beranggapan bahwa produk yang berasal dari negara China memiliki kualitas yang rendah dan harga yang murah. Hal menunjukan bahwa identitas country of origin suatu produk dapat membentuk persepsi kualitas. Hal ini sejalan dengan hasil penelitian Susmikawati dan Sunarti (2017), Dinata dkk (2015), Izzuddien dkk (2018) dan Le dkk (2017) yang menyatakan bahwa country of origin berpengaruh positif signifikan terhadap perceived quality.

\section{Faktor Country of Origin terhadap Minat beli melalui Perceived Quality}

Faktor country of origin terhadap minat beli melalui perceived quality adalah berpengaruh signifikan. Nama suatu negara sebagai indentitas country of origin dari suatu produk biasanya diasosiasikan dengan perceived quality (persepsi kualitas) suatu produk. Seperti contoh, konsumen menganggap bahwa produk fashion dari Paris berkualitas 
tinggi dan memiliki harga jual yang mahal. Sebaliknya konsumen beranggapan bahwa produk elektronik buatan China memiliki kualitas yang rendah dan harga yang murah dibandingkan dengan produk elektronik buatan Amerika. Hal ini menunjukkan bahwa identitas country of origin suatu produk merupakan hal yang penting dalam membentuk persepsi kualitas sebuah produk. Dalam penelitian ini juga menunjukkan bahwa identitas country of origin dari produk mascara Maybelline yang berasal dari negara Amerika Serikat (New York) membentuk citra positif mengenai kualitas mascara Maybelline sehingga responden dalam penelitian ini berminat membeli mascara Maybelline.

Setelah terbentuknya persepsi kualitas seseorang terhadap suatu produk, selanjutnya seseorang akan memiliki daya tarik atau minat beli terhadap suatu produk. Apabila persepsi kualitas yang dimiliki seseorang positif terhadap suatu produk, maka akan mendorong minat beli seseorang terhadap suatu produk. Sebaliknya, apabila persepsi akan kualitas sebuah produk seseorang rendah, maka akan menurunkan minat beli terhadap suatu produk. Hal ini sejalan dengan hasil penelitian Susmikawati dan Sunarti (2017), Dinata dkk (2015), dan Izzuddien dkk (2018) yang menyatakan bahwa country of origin berpengaruh signifikan terhadap perceived quality dan perceived quality berpengaruh signifikan terhadap minat beli.

\section{PENUTUP}

\section{Kesimpulan}

Berdasarkan hasil analisis data dan pembahasan hasil penelitian ini serta hasil pengujian data dan pembahasan yang telah di lakukan maka dapat di ambil suatu kesimpulan sebagai berikut :

1. Endorsement beauty vlogger berpengaruh positif signifikan terhadap minat beli produk Mascara Maybelline di Purwokerto.

2. Country of origin positif dan tidak signifikan terhadap minat beli produk Mascara Maybelline di Purwokerto.

3. Country of origin berpengaruh positif signifikan terhadap perceived quality produk Mascara Maybelline di Purwokerto.

4. Perceived quality berpengaruh positif signifikan terhadap minat beli produk Mascara Maybelline di Purwokerto.

5. Country of origin berpengaruh signifikan terhadap minat beli melalui perceived quality pada produk Mascara Maybelline di Purwokerto.

\section{Keterbatasan Penelitian}

Keterbatasan penelitian ini secara khusus diperoleh sebagai berikut :

1. Sampel yang digunakan dalam penelitian ini hanya 90 responden, sehingga tidak menutup kemungkinan akan diperoleh hasil yang berbeda jika menggunakan sampel yang lebih banyak.

2. Penelitian ini hanya dibatasi menggunakan variabel endorsement beauty vlogger, country of origin dan perceived quality. Masih banyak variabel lain yang mempengaruhi minat beli, seperti citra merek, kualitas produk, sikap konsumen, EWOM (Electronic Word of Mouth) dan kepercayaan.

\section{Saran}

1. Bagi Perusahaan

a. Sebagai endorsement beauty vlogger Maybelline, Abel Cantika harus bisa mewakili produk Maybelline dalam mempengaruhi konsumen agar tertarik membeli produk Maybelline khususnya mascara melalui keahliannya dan daya tariknya dalam mempromosikan lewat YouTube.

b. Perusahaan Maybelline dapat juga mengganti beauty vlogger jika kinerjanya kurang maksimal. 
c. Perusahaan Maybelline dapat juga meminta Abel Cantika untuk mempromosikan produk melalui media sosial seperti Instagram agar dapat mempengaruhi konsumen untuk membeli.

2. Bagi Konsumen

Untuk mencari informasi dan memahami lebih lanjut ketika akan membeli produk Mascara Maybelline maupun produk kosmetik yang lain, misalnya dengan melihat review produk yang dipaparkan oleh endorsement beauty vlogger. Sehingga ketika akan membeli produk akan tahu baik kelebihan maupun kekurangan dari suatu produk kosmetik yang akan dibeli.

3. Bagi Peneliti Selanjutnya

Berdasarkan nilai $R$-Square, variabel endorsement beauty vlogger, country of origin, dan perceived quality terhadap minat beli sebesar $24,8 \%$, maka peneilitian selanjutnya dimungkinkan untuk menambah variabel independen lain yang dapat mempengaruhi minat beli. Selain itu peneliti selanjutnya hendaknya memperbanyak sampel penelitian, tidak hanya 90 responden saja namun bisa lebih agar semakin mengetahui karakteristik suatu populasi dari banyaknya sampel yang mewakili populasi tersebut dalam perilaku konsumen secara keseluruhan.

\section{DAFTAR PUSTAKA}

Adenan, Mohd Amirul; Ali, Jati Kusuma dan Rahman, Dayang Humida Abang Abdul Rahman. 2018. Country of Origin, Brand Image and High Involvement Product Towards Customer Purchase Intention: Empirial Evidence of East Malaysian Cunsumer. JMK. Vol. 20 No. 1: 63-72.

Anggraeni, Rima Dwi; Pangestuti, Endriana dan Devita, Lussy Deasyana Rahma. 2018. Pengaruh Endorsement Beauty Vlogger terhadap Minat Beli Make Up Brand Lokal. Jurnal Administrasi Bisnis (JAB). Vol. 60 No. 1: 155-162.

Andjarwati, Anik Lestari dan Dewi, Lady Arantxa Meiliana. 2019. Pengaruh Beauty Vlog terhadap Purchase Intention dan Brand Awareness Marina Hand and Body Lotion. Jurnal Minds (Manajemen Ide dan Inspirasi). Vol. 6 No. 1: 1-18.

Ardelia dan Supriono.2017. Pengaruh Brand Creadibility dan Brand Prestige terhadap Presepsi Kualitas dan Minat Beli. Jurnal Administrasi Bisnis (JAB). Vol. 50 No. 3: 9-18.

Asdiansyuri, Ulfiyani dan Octavia, Yusi Faizathul. 2018. Pengaruh Produk Halal NonLabel terhadap Perceived Quality dan Minat beli Makanan Ringan di Mataram. Jurnal Tata Sejuta STIA Mataram. Vol. 4 No. 2: 1-10.

Berlianto, Margaretha Pink. 2019. Pengaruh Country of Origin dan Brand Image terhadap Brand Equity dan Niat Pembelian pada Produk Kosmetik. Jurnal of Business \& Applied Management. Vol. 12 No. 1: 59-106.

Blog.Alfacart.com 2019: Perbedaan Mascara Maybelline Hypercurl Asli dan Palsu, Wajib Tau Supaya Ngga Ketipu. Retrieved 28 Oktober 2019, from blog.alfacart Web site: https://www.blog.alfacart.com.

Cnbcindonesia 2018: Berita Lifestyle. (2018). Retrieved 17 Oktober 2019, from cncbindonesia Web site: https://www.cncbindonesia.co.id.

Dinata, Jovita S; Kumadji, Srikandi dan Hidayat, Kadarisman. 2015. Country of Origin dan Pengaruhnya terhadap Persepsi Kualitas dan Minat Beli. Jurnal Administrasi Bisnis (JAB). Vol.25 No:1: 1-8.

Ghozali, Imam., dan Latan, Hengky. 2015. PARTIAL LEAST SQUARE Konsep, Teknik dan Aplikasi Menggunakan Program SmartPLS 3.0. Semarang: Undip.

Hutapea, Meiliana Mutiara Desmonda. 2016. Pengaruh Vlogger dan Brand Image: Survei Pengaruh Beauty Vlogger sebagai Endorser terhadap Brand Image The Body 
Shop. [Skripsi]. Departemen Ilmu Komunikasi Fakutlas Ilmu Sosial dan Politik Universitas Gadjah Mada Yogyakarta.

Izzuddien, Syihab; Mawardi, M.Kholid dan Bafadhal, Aniesa Samira. 2018. Pengaruh Country Of Origin terhadap Presepsi Kualitas Serta Dampaknya Kepada Minat Beli Sepatu Wakai. Jurnal Administrasi Bisnis (JAB). Vol. 64 No. 1: 188194.

Kotler, Philip dan Keller, Kevin Lane. 2009. Manajemen Pemasaran Jilid 1. Jakarta: Erlangga.

2009. Manajemen Pemasaran Jilid 2. Jakarta: Erlangga.

Le, Hoang TPM; Nguyen, Phuong V; Dinh, Hophi dan Dang, Chi Na. 2017. Effect of Country of Origin and Product Features on Customer Purchase Intention: A Study of Imported Power Milk. Academy of Marketing Studies Journal. Vol. 21 No. 1: 1-19.

Li, Cheng-Ping. 2017. Effect of Brand Image, Perceived Price, Perceived Quality, and Perceived Value on The Purchase Intention Towards Sport and Tourism Products of The 2016 Taichung Internasional Travel Fair. The Journal of International Management Studies. Vol. 12 No. 2: 97-107.

Liputan6.com 2018: Abel Cntika Beauty Vlogger Nominator XYZ Day. Retrieved 29 Oktober 2019, from m.liputan6.com Web site: https://www.m.liputan6.com.

Loreal.co.id 2019: Divisi Produk Konsumen Maybelline New York. Retrieved 26 Desember 2019, from loreal.co.id Web site: https://www.loreal.co.id.

Maybelline 2018: Maybelline Collection. (2018). Retrieved 23 November 2018, from Maybelline Indonesia Web site: https://www.maybelline.co.id.

M.beautynesia.id 2019: 6 Produk Maybelline Favorit Para Beauty Vlogger. Retrieved 29 Oktober 2019, from Beautynesia Web site: https://www.m.beautynesia.id.

Priansa, Donni Juni. 2017. Perilaku Konsumen dalam Persaingan Bisnis Kontemporer. Bandung: ALFABETA cv

Sinaga, Rumondang Eliza Maria dan Kusumawati, Andriani. 2018. Pengaruh Youtube Beauty Vlogger terhadap Minat Beli Konsumen dan Dampaknya terhadap Keputusan Pembelian Produk. Jurnal Aministrasi Bisnis (JAB). Vol. 63 No. 1: 187-196.

Rafida, Veni. 2015. Pengaruh Country of Origin terhadap Minat Beli dengan Perceived Quality sebagai variabel intervening. Jurnal Pendidikan Tata Niaga. Vol. 3 No. 2:1-10.

Schiffman, Leon G. dan Kanuk, Leslie Lazar. 2018. Perilaku Konsumen Edisi 7. Jakarta Barat: PT Indeks.

Shimp, Terence A. 2014. Komunikasi Pemasaran Terpadu dalam Periklanan dan Promosi Edisi 8. Jakarta: Salemba 4.

Sigma Research 2017: Tren dan Perilaku Pasar Kosmetik Indonesia. Retrieved 23 Desember 2019, from Sigma Research Web site: https://sigmareseacrh.co.id.

Sugiyono. 2015. Metode Penelitian Manajemen. Yogyakarta: ALFABETA cv.

Sulianto. 2018. Metode Penelitian Bisnis. Yogyakarta: ANDI.

Sunarti; Wibowo, Edi dan Utami, Setyaningsih Sri. 2019. Pengaruh Beauty Vlogger terhadap Minat Beli produk Kosmetik Wardah dengan Citra Merek sebagai Variabel Mediasi. Jurnal Ekonomi dan Kewirausahaan. Vol. 9 No. 4: 578589.

Susmikawati, Yunis Nadhifah dan Sunarti. 2017. Pengaruh Country of Origin terhadap Perceived Quality dan Minat Beli Konsumen. Jurnal Administrasi Bisnis (JAB). Vol. 49 No. 2: 88-95. 
Tansil, Michell dan Tielung, Maria V.J. 2014. The Effect of Perceived Price and Perceived Quality on Purchase Intention at Shmily Cupcakes Store Manado. Journal EMBA. Vol. 2 No. 3: 1290-1299.

Tjiptono, Fandy dan Chandra, Gregorius. 2017. Pemasaran Strategik Edisi 3. Yogyakarta: ANDI.

Tjiptono, Fandy. 2015. Strategi Pemasaran Edisi 4. Yogyakarta: ANDI.

Top Brand Award 2014 : Top Brand Inde]x 2014 Fase 1. (2014). Retrieved 23 November, 2018, from Top Award Web Site : http://www.topbrand-award.com/top-brandsurvey/survey-result/top_brand_index_2015_fase_1: Top Brand 2014.

Top Brand Award 2015 : Top Brand Index 2015 Fase 1. (2015). Retrieved 23 November, 2018, from Top Award Web Site : http://www.topbrand-award.com/top-brandsurvey/survey-result/top_brand_index_2015_fase_1: Top Brand 2015.

Top Brand Award 2016 : Top Brand Index 2016 Fase 1. (2016). Retrieved 23 November, 2018, from Top Award Web Site : http://www.topbrand-award.com/top-brandsurvey/survey-result/top_brand_index_2016_fase_1: Top Brand 2016.

Top Brand Award 2017 : Top Brand Index 2017 Fase 1. (2017). Retrieved 23 November, 2018, from Top Award Web Site : http://www.topbrand-award.com/top-brandsurvey/survey-result/top brand index 2017 fase 1: Top Brand 2017.

Top Brand Award 2018 : Top Brand Index 2018 Fase 1. (2018). Retrieved 23 November, 2018, from Top Award Web Site : http://www.topbrand-award.com/top-brandsurvey/survey-result/top_brand_index_2018_fase_1: Top Brand 2018.

Top Brand Award 2019 : Top Brand Index 2019 Fase 1. (2019). Retrieved 29 September, 2019, from Top Award Web Site : http://www.topbrand-award.com/top-brandsurvey/survey-result/top_brand_index_2018_fase_1: Top Brand 2019.

Widodo, Wulan Deasy Puspita Sari dan Mawardi, M. Kholid. 2017. Pengaruh Beauty Vlogger terhadap Source Caracteristic Serta Dampaknya terhadap Purchase Intention. Jurnal Administrasi Bisnis (JAB). Vol. 47 No. 1: 63-69. 